\title{
Vertical activity patterns of free-swimming adult plaice in the southern North Sea
}

\author{
E. Hunter ${ }^{1, *}$, J. D. Metcalfe ${ }^{1}$, C. M. O'Brien ${ }^{1}$, G. P. Arnold ${ }^{1}$, J. D. Reynolds ${ }^{2}$ \\ ${ }^{1}$ Centre for Environment, Fisheries and Aquaculture Science, Lowestoft Laboratory, Lowestoft NR33 0HT, Suffolk, UK \\ ${ }^{2}$ Centre for Ecology, Evolution and Conservation, School of Biological Sciences, University of East Anglia, Norwich NR4 7TJ, UK
}

\begin{abstract}
Analysis of continuous behaviour records of adult female plaice Pleuronectes platessa tagged with electronic data storage tags, and released in the southern North Sea, has yielded new insights into spatial and temporal variation in vertical activity (swimming). Here we describe migration-linked changes in vertical activity patterns observed from 31 plaice released between December 1993 and February 1997. Fish migrations of up to $220 \mathrm{~d}$ were reconstructed using the tidal location method. Analysis of the periodicity of activity revealed high levels of vertical activity during the southward spawning migration into Southern Bight and the eastern English Channel following release in December and January. We observed spatially varying, migration-linked changes in vertical activity, with a tidal pattern of vertical activity during the pre- and post-spawning migrations and a circadian period of rhythmicity in the spawning grounds. Circadian periodicity was dominant in 23 of 31 individuals $(74 \%), 13$ of which also demonstrated significant $12 \mathrm{~h}$ periodicity. The other 8 fish exhibited a dominant $25 \mathrm{~h}$ periodicity. A significant $336 \mathrm{~h}(14 \mathrm{~d})$ rhythm was observed in the averaged population data, in phase with the spring-neap cycle, with periods of reduced activity associated with times of expected high tides. Our results provide important information about systematic changes in migration-linked behaviour in plaice, and also illustrate how the accessibility of plaice to capture by trawling may vary in space and in time.
\end{abstract}

KEY WORDS: Plaice - Migration - Data storage tags · Vertical activity · Stock assessment · Accessibility · Fisheries

Resale or republication not permitted without written consent of the publisher

\section{INTRODUCTION}

Despite intensive exploitation by fisheries over the past century, we are only now beginning to understand the often complex spatial distributions of exploited marine fish stocks (e.g. McQuinn 1997), and how these change on a seasonal basis (Metcalfe et al. 2002). An understanding of the spatial and temporal variation in both horizontal migration and vertical activity patterns is important to determine not only where fishes are located in space and time, but also to determine how vulnerable these fishes are to commercial exploitation (Harden Jones 1974, Walsh 1991, Jørgensen 1997, Aglen et al. 1999, Kell et al. 2004). However, until recently, observations of the behaviour of these fish have been derived largely from indirect observations, taken, for example, from research survey sampling programmes (Michalsen et al. 1996, Aglen et al. 1999).

Problems involved in the estimation of fish abundance, including extrapolations from scientific surveys, have been well documented (Godø 1994, Michalsen et al. 1996, Aglen et al. 1999). However, the increasingly routine use of electronic data storage tags in fisheries research have revealed new features of behaviour that may help to overcome these difficulties (Arnold \& Dewar 2001, Metcalfe et al. 2002). For example, electronic tags have successfully described regional and seasonal variations in the migratory activity of Atlantic cod Gadus morhua (Godø \& Michalsen 2000, Righton et al. 2001, Stensholt 2001, Righton \& Metcalfe 2002). Behavioural information of this type can significantly improve the interpretation of survey 
data (Godø 1994, Hjellvik et al. 2001), notably where systematic changes in behaviour can be predicted (D. Righton et al. unpubl.).

The plaice Pleuronectes platessa occurs in the North Sea from the littoral zone down to $200 \mathrm{~m}$ (Wheeler 1969, Albert et al. 1998), although it is fished routinely from waters shallower than $100 \mathrm{~m}$ (Albert et al. 1998). The behaviour rhythms of juvenile plaice are well understood (reviewed by Gibson 1997). Age zero and $1 \mathrm{yr}$ old plaice in the western Wadden Sea use tidal transport to make feeding excursions onto mud flats (Kuipers 1973). Similar excursions have been observed on sandy shores off the north-west coast of Scotland (Gibson 1973). Information on the late larval stages show that they utilise tidal transport to move from the North Sea into the nursery grounds of the Wadden Sea before metamorphosis takes place (Creutzberg et al. 1978, Rijnsdorp et al. 1985). The environmental signal that entrains circatidal rhythms in juvenile plaice is known to be hydrostatic pressure (Gibson 1982).

Diel rhythms in the activity of adult plaice have been demonstrated in several laboratory studies in both constant conditions and in light-dark cycles (De Groot 1964, 1971, Verheijen \& De Groot 1967, Gibson et al. 1978). Most of these studies have demonstrated increased surface swimming activity during darkness, and short-distance swimming on or near the bottom during light periods. Gibson et al. (1978) described depressed bottom activity and increased surface swimming during constant darkness, using plaice which had spent 25 wk acclimating in the laboratory. Page (1996), who examined the activity of plaice in the laboratory less than $12 \mathrm{~h}$ following capture, showed evidence of both $12 \mathrm{~h}$ (circatidal, $\mathrm{n}=6$ ) and $24 \mathrm{~h}$ (circadian, $n=3$ ) rhythms of activity among a total of 12 fish studied. Although these results reveal the possible behaviour patterns exhibited by wild plaice, it is difficult to extrapolate these relatively limited observations to wild populations over periods that span migratory cycles.

Patterns of the vertical activity of plaice (i.e. activity off the seabed) in the natural environment have been observed mainly through acoustic tracking experiments, whereby individual fish were tracked for periods of 1 wk or less (Greer Walker et al. 1978). Pre- and post-spawning migrations are achieved by the adoption of a circatidal pattern of activity termed 'selective tidal stream transport' (Greer Walker et al. 1978, Harden Jones et al. 1979), with southward-migrating plaice selectively leaving the seabed on south-flowing tides and swimming downtide to within $\pm 60^{\circ}$ of the tidal stream axis (Buckley \& Arnold 2001). These fish return to the sea bottom before slack water, where they remain for the duration of the opposing tide; the cycle is then repeated when the tide changes again.
The facultative use of transporting tides allows rapid and efficient movement between geographically distant feeding and spawning areas. Plaice then appear to adopt diel patterns of behaviour in the spawning grounds (Arnold 2000, Solmundsson et al. 2003). Peak spawning occurs in the southern North Sea between December and March (Harding et al. 1978), with spawning areas concentrated in the Southern Bight and eastern English Channel (see Fig. 4 of Hunter et al. 2004a).

Tracking studies conducted during the summer, when plaice occupy the central North Sea feeding grounds, have also demonstrated diel patterns of vertical activity (Arnold 1981, Arnold \& Cook 1984). Since the tidal cycle is out of phase with that of the day-night cycle, it appears that the adoption of diel patterns of vertical activity allows the random distribution of the fish around the feeding and spawning areas (Harden Jones et al. 1979, Arnold 1981).

While these data have provided snapshots of the migratory behaviour of southern North Sea plaice, our aim in the current work was to examine vertical activity over full migration seasons. Electronic tags have already been successfully used to describe plaice migration (Metcalfe \& Arnold 1997, Hunter et al. 2003b, 2004a,b), population biology (Hunter et al. 2004a) and spawning activity (Solmundsson et al. 2003). In the present study, we aimed to determine (1) whether the vertical activity of plaice changes systematically in a way that can be linked with their seasonal migration, and (2) whether such changes in vertical activity potentially impact assessments of stock abundance based on research vessel survey data. We used data from 31 adult female plaice equipped with electronic data storage tags, which provided a unique opportunity to observe continuous records of vertical movement for periods of up to $220 \mathrm{~d}$.

\section{MATERIALS AND METHODS}

Electronic data-storage tags. In total, 302 plaice Pleuronectes platessa were tagged with CEFAS Mk 1 electronic data storage tags and released in the southern North Sea in 6 batches between December 1993 and February 1997, between latitudes 52 and $53^{\circ} \mathrm{N}$. Full details of the capture, tagging and release of the plaice used in the current experiments are given elsewhere (see Hunter et al. 2004b), as are technical details of the tags (see Metcalfe \& Arnold 1998). Because of the size of the tags, only mature female plaice (which are larger than males) with a minimum total length of $40 \mathrm{~cm}$ were tagged. The tags were programmed to record temperature daily (at 00:01 h GMT), and pressure at 10 min intervals. 
Data from 51 returned tags were downloaded and pressure was converted to depth. Of these, 37 recorded behavioural data for all or part of the period when the fish were at liberty; 31 tags recorded between 8 and $220 \mathrm{~d}$ of data (see Table 1), and these were used for analysis.

The southern North Sea seabed consists of gently undulating sandy sediments, and rarely exceeds $40 \mathrm{~m}$ depth (Charnock et al. 1994). Plaice leaving the seabed tend to do so at a steep ascent angle (see Fig. 4 of Metcalfe \& Arnold 1998), and this feature of plaice swimming coupled with the 10 min recording interval provided a clear record of when the plaice were actively swimming in midwater or resting on the seabed (Hunter et al. 2003 a). To facilitate analysis, the depth record was converted into a binary file of activity $(=1$ ) versus inactivity (resting on seabed, $=0$ ). To allow statistically valid interpretation of the results, the binary record was grouped hourly (Dörrscheidt \& Beck 1975). Hourly counts ranged from zero activity up to a total score of 6 , whereby it was assumed that the fish spent the whole hour swimming. These data provided the continuous time-series for analysis (see next subsection).

We were unable to identify atypical behaviour patterns immediately following release; however, as a precaution, the first $2 \mathrm{~d}$ of data were removed from each activity record to eliminate behaviour patterns caused by tagging procedures. To examine population-wide activity patterns, overlapping time-series were pooled to create records of average population activity (Table 1). This provided 2 population data sets: Releases 1 and $2(\mathrm{n}=15)$, and Releases 4 and 5 ( $\mathrm{n}=16)$.

Periodogram and actogram analysis. Data were analysed to determine the occurrence of vertical activity rhythms, and to establish the dominant period of rhythmicity where present, using customised software in S-Plus (Mathsoft). Analysis of biological time-series frequently employs periodogram analysis (Enright 1965, Harris \& Morgan 1983). The technique utilises a Buys-Ballot table in which time-series are written in successive rows, the number of columns being determined by the period investigated. The periodogram statistic, Qp, is calculated as the standard deviation of the column means (Sockolove \& Bushell 1978). The periodogram is a plot of $\mathrm{Qp}$ as a function of period. Periodogram analysis allowed the rapid identification of significant behaviour rhythms over a predetermined range. The vertical axis provides an indication of the strength of the rhythm at each wavelength over the specified range, such that the highest peak indicates the periodicity of the predominant rhythm, with other peaks indicating rhythmicity of a lower intensity (see next subsection).
We used Dörrscheidt \& Beck's (1975) modified $Q_{p}$ periodicity statistic, $q(p)$, to derive confidence limits below which $q(p)$ was expected with a probability of 0.95. This was valid for activity rhythms of between approximately 10 and 30 h (Sokolove \& Bushell 1978), and allowed discrimination between spurious values of $q(p)$ and those resulting from real periodic components. The highest significant value of $q(p)$ generally represents the dominant rhythmicity within the specified period. However, all significant periods were tested for representativeness of the true period of activity using a simple analysis of homogeneity (Dörrscheidt \& Beck 1975). A linear regression fit and slope estimate was added to the analysis of homogeneity profiles to aid identification of oscillations and trends in the parameters.

Data from individual tags were analysed within the range 2 to $50 \mathrm{~h}$ (to discriminate circadian rhythms with $24 \mathrm{~h}$ periodicity, from circatidal rhythms with an approximate $12.5 \mathrm{~h}$ periodicity in the southern North Sea. Where plaice were active during just 1 tidal period per day, e.g. during the hours of darkness only, a $25 \mathrm{~h}$ periodicity would be recorded). For population data, higher-order periodicities were examined over a range of up to $400 \mathrm{~h}$ to allow identification of spring-neap cycles with a periodicity of approximately $14 \mathrm{~d}$ (336 h) in the southern North Sea. Where significant periods were identified, the length and duration of periods of activity were examined by plotting the level of activity (activity profile) against the period.

Double-plot actograms were produced for each fish (see next subsection). Activity on 2 consecutive days was plotted directly below the subsequent $2 \mathrm{~d}$ activity. This allowed rapid, uninterrupted visualisation of dayto-day transitions in activity patterns. For longer records, actograms provided a rapid visual assessment of behavioural changes in successive months.

Visual interpretation of periodogram and actogram analyses. Previous studies have already suggested that plaice adopt circadian and circatidal activity patterns at different stages of the annual migration cycle (Arnold \& Metcalfe 1996, Arnold 2000), and that tidally transported plaice sometimes use only those tides occurring during the hours of darkness (Arnold \& Metcalfe 1996). To aid visual interpretation of the periodograms and double-plot actograms we constructed artificial files containing stereotypical activity data, using random, circadian (16 h activity followed by $8 \mathrm{~h}$ rest), circatidal ( $6.5 \mathrm{~h}$ activity followed by $6.5 \mathrm{~h}$ rest) and tidal-at-night data (Fig. 1). Circadian behaviour was defined as $16 \mathrm{~h}$ activity followed by $8 \mathrm{~h}$ rest to mimic the long winter night in the North Sea at the time when the fish were released. Then stereotypical data sets were used to generate actograms and peri- 


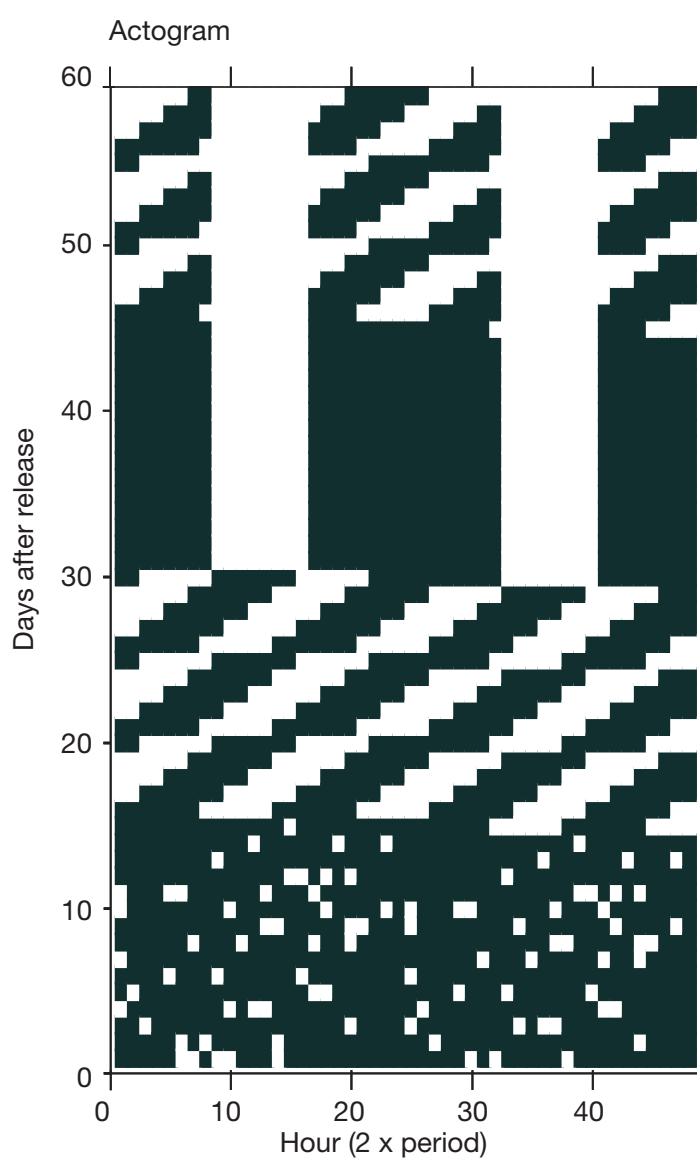

Periodogram

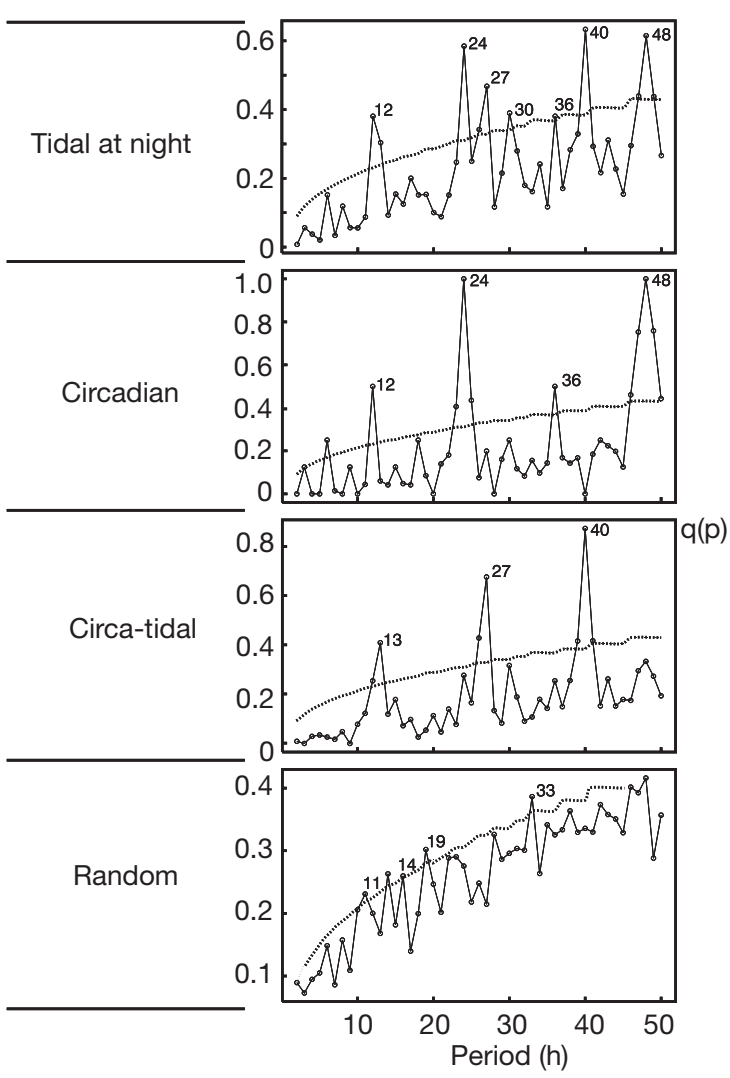

Fig. 1. Pleuronectes platessa. Double-plot actogram (left), and periodogram analysis (right) of artificial files containing stereotypical activity data to illustrate $16 \mathrm{~d}$ blocks of (1) tidal-at-night, (2) circadian (16 h activity followed by $8 \mathrm{~h}$ rest), (3) circatidal (6.5 h activity followed by $6.5 \mathrm{~h}$ rest), and (4) random activity. In double-plot actogram, black = vertical activity, and white = activity on seabed. In periodogram, dotted line represents approximate 0.01 significance level; numbers above peaks denote significant periodicities. $q(p)$ : modified periodicity statistic. See 'Materials and methods' for details

odograms illustrating precise vertical activity rhythms, to aid visual interpretation of the results (Fig. 1). Significant periodicities are visible as peaks occurring above the approximate 0.01 significance level (dotted line, in periodograms of Fig. 1), e.g. $24 \mathrm{~h}$ in the case of circadian behaviour.

Individual actograms were interpreted in association with the previously reconstructed movements of the same plaice (see Hunter et al. 2004b), determined using the tidal location method (Hunter et al. 2003a). The tidal location method estimates geographical location based on the time of high water and tidal range, measured by the depth (pressure) sensor when a fish remains motionless on the seabed over a full tidal cycle (or longer).

Spatial and temporal variation in swimming activity. Using previously reconstructed ground-tracks of migrating plaice (see Hunter et al. 2004b), daily locations were assigned to ICES rectangles, and plots were made of the total number of hours spent in midwater per rectangle per month, divided by the number of fish days of occupancy, thereby establishing a crude quantification of spatial and temporal variation in the swimming activity of the plaice.

\section{RESULTS}

The number of hours spent in midwater per day, averaged by month, varied over time and among fish (Fig. 2). The plaice spent $1 / 4$ to $1 / 3$ of their time swimming in midwater following release in December and January (Fig. 2). However the number of hours swimming had declined to virtually zero hours by May. The results from Release Batch 6 are from a single individual which became active during the final $9 \mathrm{~d}$ before recapture on June 1997 (mean $=4.6 \pm 2.4 \mathrm{~h} \mathrm{SD}$, Table 1). 


\section{Periodogram analysis of individual fish}

Of the fish examined, 23 (74\%) exhibited dominant circadian, i.e. $24 \mathrm{~h}$, rhythmicity (Table 1); 13 of these also demonstrated significant $12 \mathrm{~h}$ periodicity, but with a lower value of $q(p)$. The other 8 fish exhibited a dominant $25 \mathrm{~h}$ period of activity. The $25 \mathrm{~h}$ period was associated with shorter behaviour records (mean $=40.4 \pm$ $29.7 \mathrm{~d}$ vs mean $=101 \pm 69.6 \mathrm{~d}$, Student's $t$-test, $\mathrm{p}=$
0.0245). In half of these fish, the dominant $25 \mathrm{~h}$ rhythm was associated with a significant periodicity of $12 \mathrm{~h}$ at a lower value of $q(p)$ and, for Plaice No. 17, a periodicity of $13 \mathrm{~h}$ (Table 1). Other significant periods identified $(6,8,16$, and $22 \mathrm{~h})$ had very low values of $q(p)$ relative to the dominant periodicities, and were often only just significant. In all cases, the dominance of the higher value of $q(p)$ was confirmed by analysis of homogeneity.

Table 1. Pleuronectes platessa. Activity rhythms of plaice tagged with electronic data storage tags. Values of modified periodicity statistic, q(p), are shown for 12 and $24 \mathrm{~h}$ and other significant periodicities ('Other') of activity (see 'Materials and methods' for details). Shading indicates dominant rhythms. Days (n): no. of days of data; TL: total length

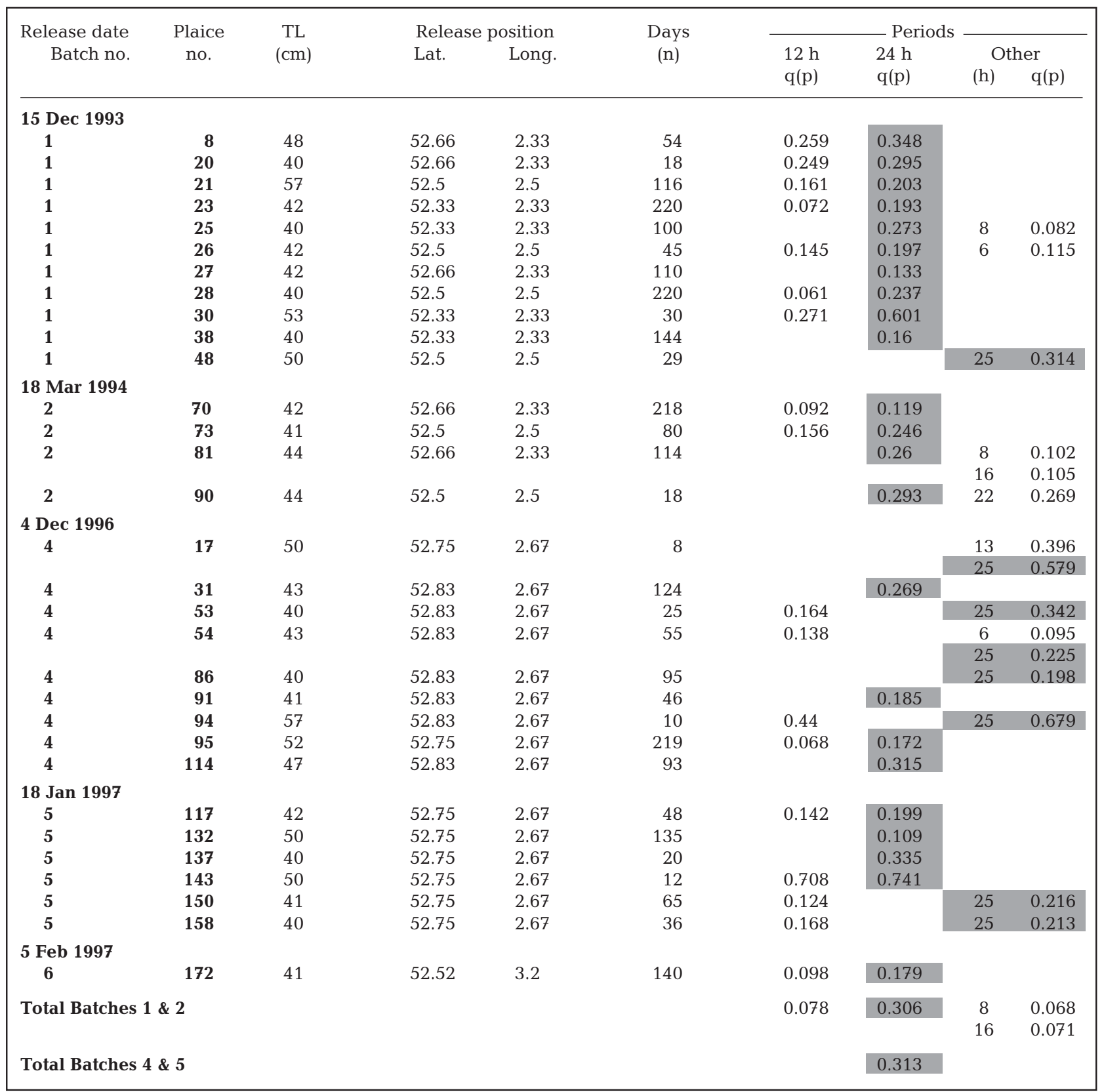




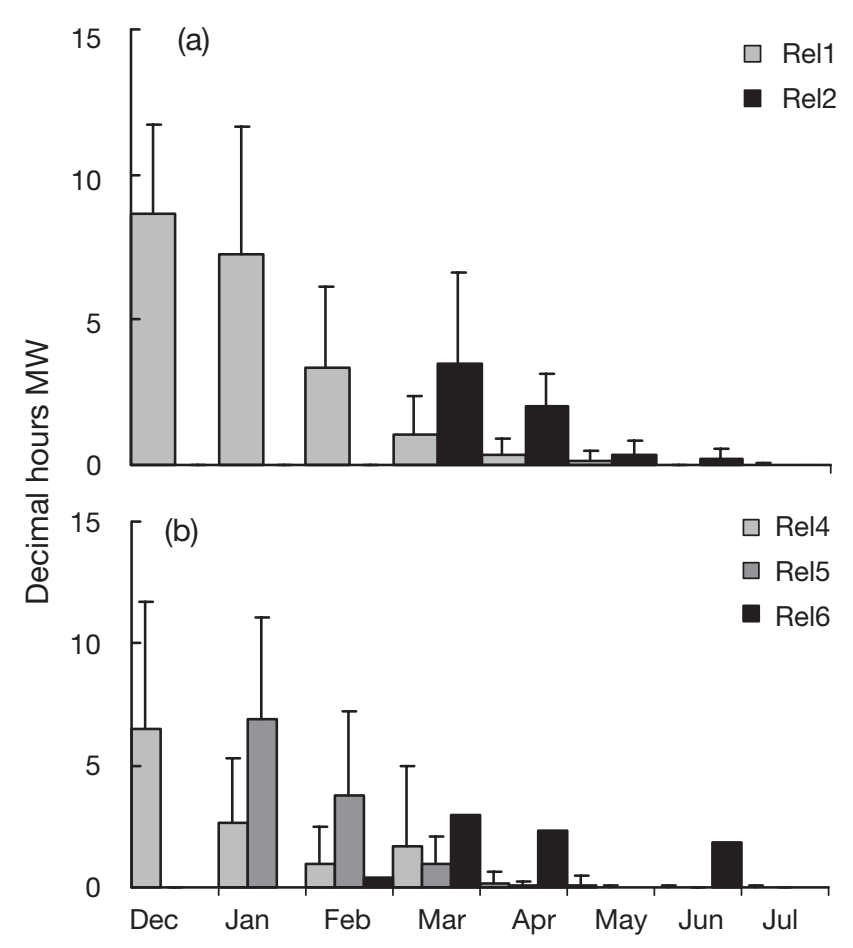

Fig. 2. Pleuronectes platessa. Monthly average (+SE) of the total number of hours spent daily in midwater (MW). Data refer to area in the eastern English Channel and southern North Sea bounded by latitudes 49.5 and $55^{\circ} \mathrm{N}$. Months of August to November were excluded due to lack of tags at liberty during this period. (a) Releases 1 and 2; (b) Releases 4 to 6

\section{Actogram analysis of individual fish}

Actogram analysis revealed that vertical activity varied with time and among individuals. To illustrate spatial and temporal variation in vertical activity, actograms and ground-tracks from 3 plaice that had recorded entire pre- and post-spawning migrations are shown in Fig. 3 (see Hunter et al. 2004b for full details of reconstructed plaice ground-tracks). From the point of release, the fish migrated south into the spawning grounds in the eastern English Channel, then back again into the Southern Bight. Examination of actograms (Fig. 3a) and ground-tracks (Fig. 3b) revealed that phases of predominantly tidal activity were associated with movement of the fish both into the eastern English Channel during the pre-spawning migration (9 to $14 \mathrm{~d}$ ), then again during the postspawning migration when the fish returned northwards into the Southern Bight (12 to 25 d, Fig. 3b). There was a distinct change in behaviour to circadian activity (or minimal vertical activity for Plaice 21, Fig. 3a), when the fish were located in the eastern English Channel spawning grounds (11 to $55 \mathrm{~d}$ ). Following the post-spawning migration, Plaice 21 and 31 appeared to cease migrating at approximately $53.5^{\circ} \mathrm{N}$, $2^{\circ} \mathrm{E}$ (after 57 and $123 \mathrm{~d}$ respectively, Fig. 3), after which vertical activity was minimal.

These 3 plaice (Nos. 8, 21 and 31) provide examples of full annual migrations; 6 more plaice were recaptured in the eastern English Channel during the spawning period (see Hunter et al. 2004b). However 2 of the 11 plaice that reached the eastern English Channel did not exhibit a northward post-spawning migration. Plaice 28 (Fig. 4a) migrated south into the Channel within $20 \mathrm{~d}$ of release. The pre-spawning migration was achieved using circatidal vertical activity, indicative of selective tidal stream transport, which was then replaced in the spawning area by circadian activity. However, this plaice then remained in the Channel until it was captured in August. Although the plaice exhibited minimal vertical activity throughout the post-spawning phase, analysis (not shown) indicated that vertical excursions occurred with circatidal periodicity.

Not all tagged plaice migrated into the English Channel. Fig. 4 shows 2 examples. Plaice 38 initially remained close to the East Anglian coastline, then started to migrate northwards after $40 \mathrm{~d}$. It reached its southern extremity on Day 37 (Fig. 4b), but its activity throughout this initial period was random. Random vertical activity of this type would translate to non-linear horizontal movement. This phase was followed by $14 \mathrm{~d}$ of circatidal, then $36 \mathrm{~d}$ of tidal-at-night activity, following which the fish had reached the northern limit of its migration. The final phase recorded by the tag was characterised by limited circadian vertical activity and minimal horizontal movement.

Plaice 172 was released further to the east than the other tagged fish, and later in the spawning season (on 5 February 1997), and may have been released in a spawning ground. During the $48 \mathrm{~d}$ after release (Fig. 4), it demonstrated limited swimming activity, with no detectable periodicity in vertical movement. This may have corresponded to the spawning period of the fish (although no circadian rhythm was detected), and was followed by a $27 \mathrm{~d}$ phase of tidal-at-night swimming. The fish was then largely inactive for the following $45 \mathrm{~d}$, before exhibiting a brief period of circadian activity prior to its capture on 26 June 1997.

\section{Population-wide behaviour rhythms}

Periodogram analysis of the averaged population data reflected the principal components of rhythmicity observed for the individual fish (i.e. $24 \mathrm{~h}$ peaks of activity, Table 1). To further examine the representativeness of $24 \mathrm{~h}$ as the periodicity for the averaged population data, analysis of homogeneity, with a period of 
(a)

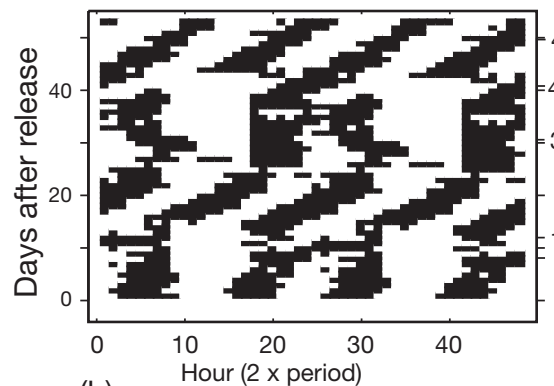

(b)

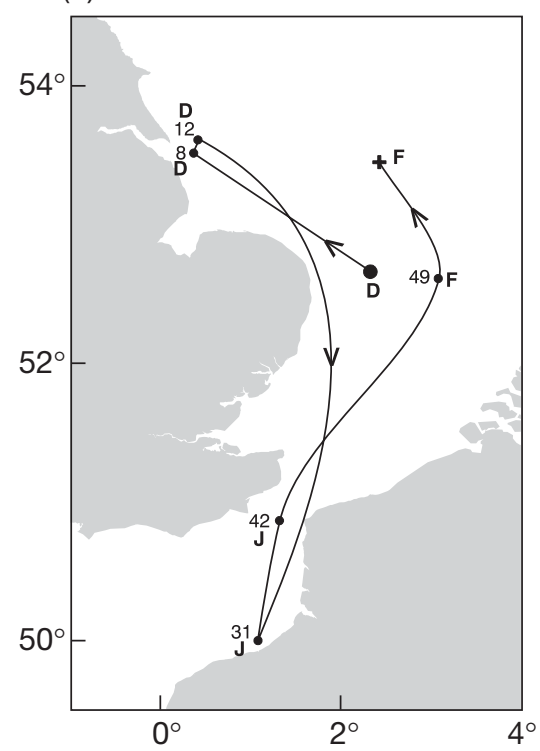

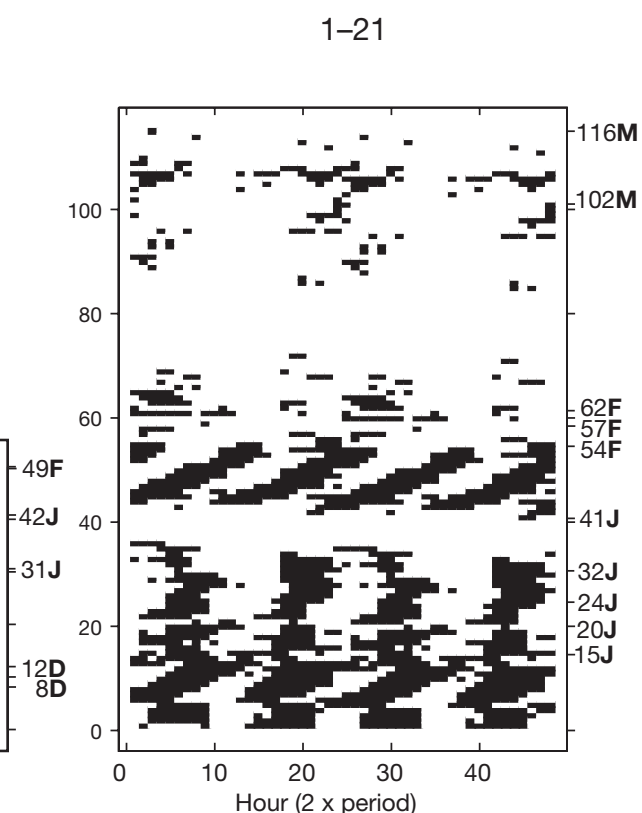
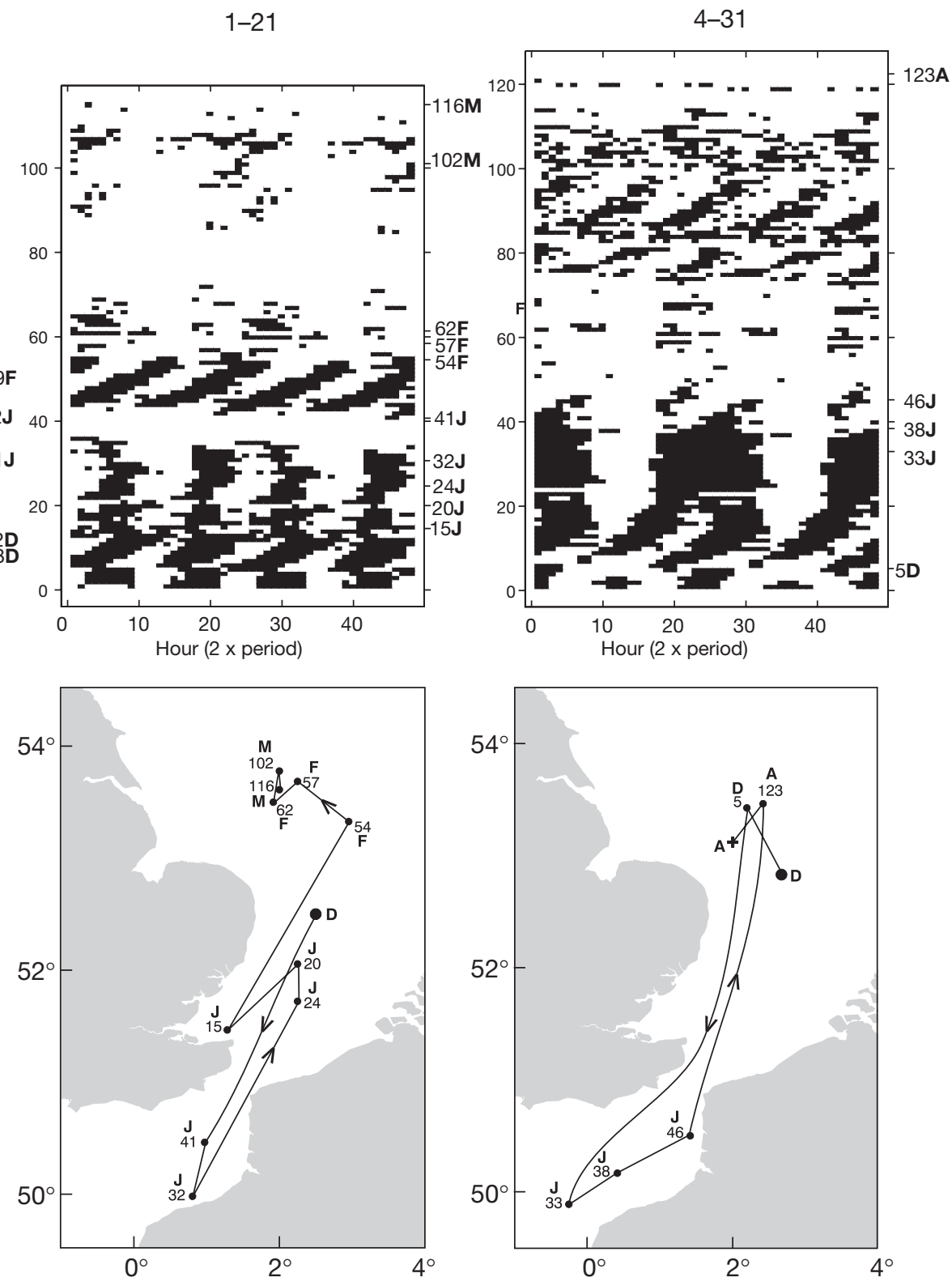

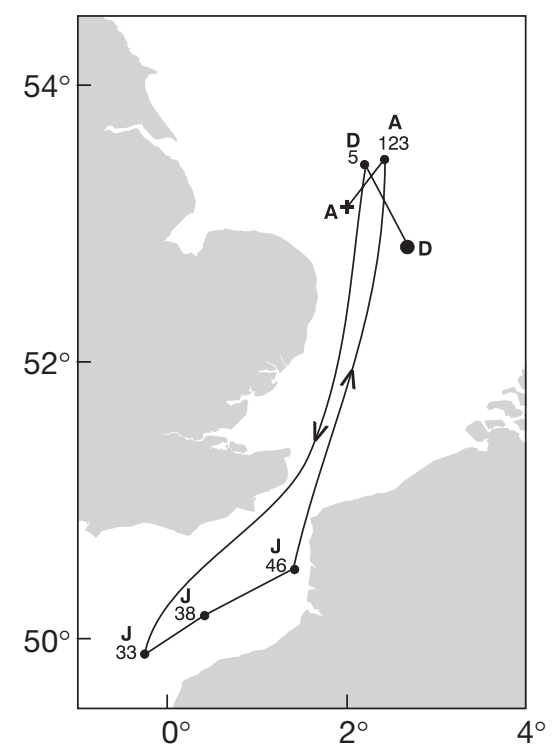

Fig. 3. Pleuronectes platessa. (a) Double-plot actograms and (b) reconstructed movements of plaice tagged with electronic data storage tags. Examples shown migrated from Southern Bight into eastern English Channel to spawn, then back again. Numbers above graphs: Release batch-fish no. (Table 1). In (a) left-hand ordinate indicates number of days after release minus $2 \mathrm{~d}$ (see 'Materials and methods'), right-hand ordinate day and month during which positions were estimated (D: December; J: January; F: February; M: March; A: April). (b) Black lines: suggested migration route of each fish; arrows show direction of movement. Larger circle: release position; small circles: positions estimated using tidal location method (see 'Materials and methods' for details); (+) recapture position (N.B. no recapture position was available for Plaice 21); months labelled as for (a)

$24 \mathrm{~h}$, was performed. For combined Releases 1 and 2 (regression estimate $=0.22$ ), and Releases 4 and 5 (regression estimate $=0.23$ ), the general lack of fit and large number of sections suggested that supplementary periodicity might exist within the data. Periodogram analysis with a period of between 2 and $400 \mathrm{~h}$ revealed a dominant period of $336 \mathrm{~h}(14 \mathrm{~d})$ in each case
(Fig. 5a), suggesting that activity was related to the spring-neap tidal cycle. Activity profiles for the $336 \mathrm{~h}$ period suggested peaks in activity after approximately $4 \mathrm{~d}$ for Releases 1 and 2, and after approximately $10 \mathrm{~d}$ for Releases 4 and 5, suggesting that low levels of vertical activity were associated with the times of expected high tides at new and full moon (Fig. 5b). 
(a)
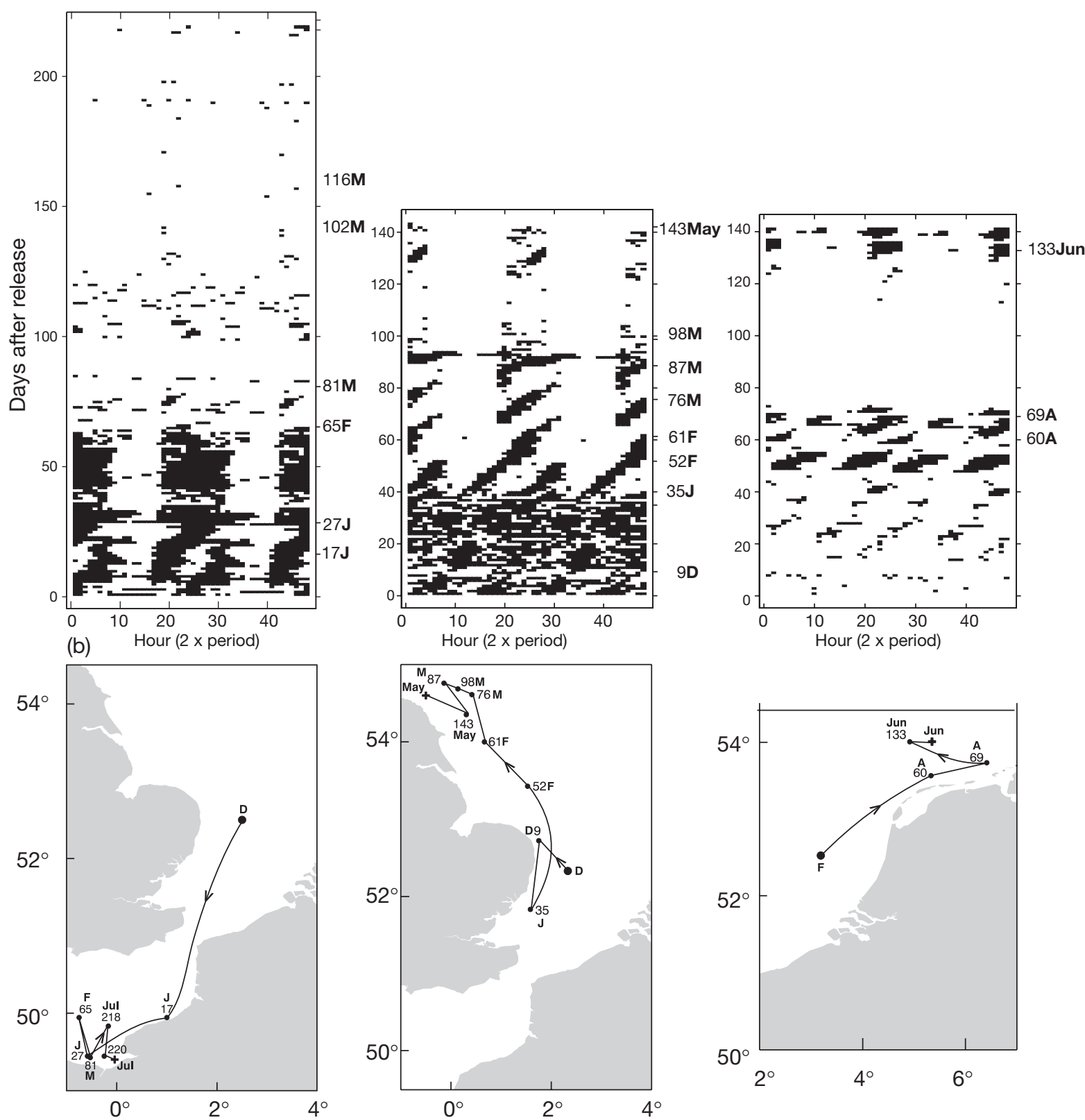

Fig. 4. Pleuronectes platessa. (a) Double-plot actograms and (b) reconstructed movements of plaice tagged with electronic data storage tags. Examples of plaice migration routes. Further details as in legend to Fig. 3

\section{Spatial and temporal variation in swimming activity}

The average number of hours each fish spent in midwater in each ICES rectangle per month is plotted in Fig. 6. As observed previously (Fig. 2), the fish spent more time swimming during December and January. High levels of swimming activity were distributed throughout the area from which we obtained data, although activity was slightly higher towards the south (Fig. 6). Levels of vertical activity observed during February and March were considerably less than those observed during the pre-spawning migration, and distribution of this activity follow the northward migration. The majority of plaice appear to have reached their feeding grounds by April, from which time the level of swimming activity dropped off steeply across the feeding range. 
(a)

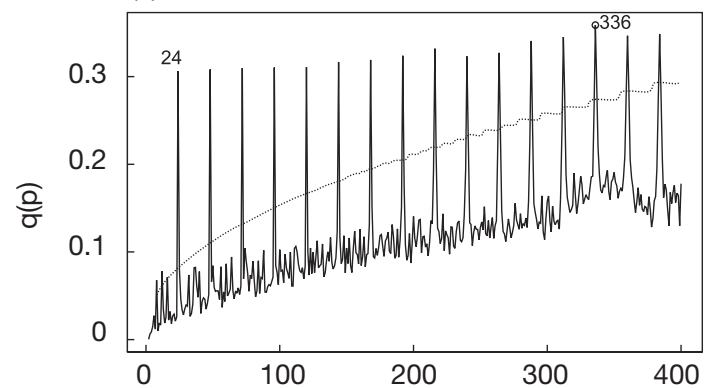

(b)

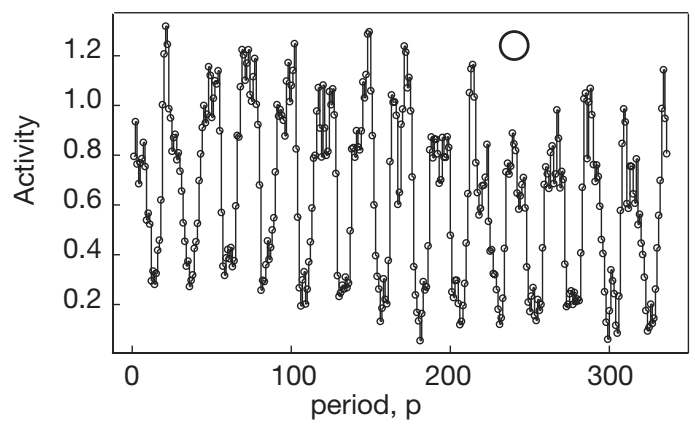

Releases 4 and 5
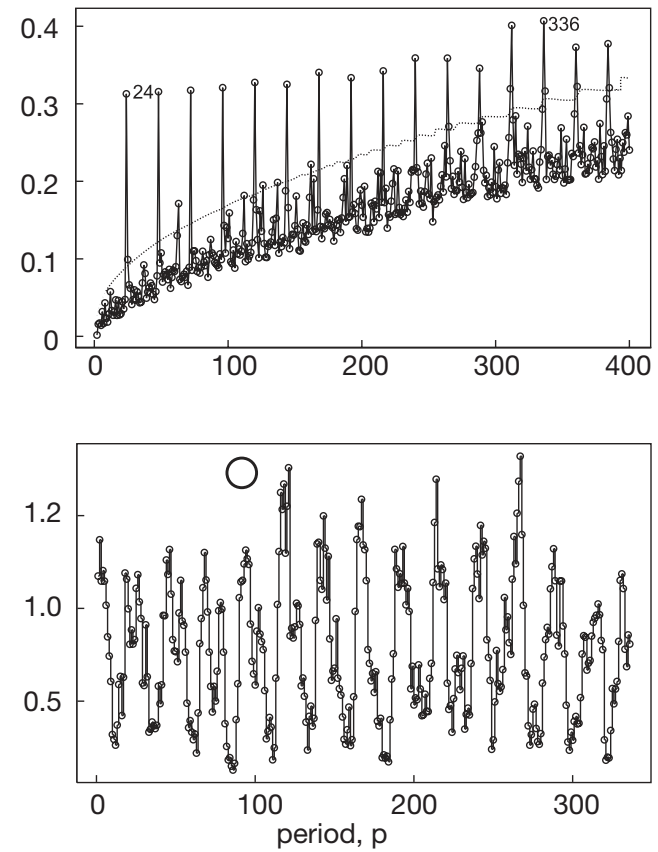

Fig. 5. Pleuronectes platessa. (a) Periodograms and (b) activity profiles illustrating population-wide rhythms of activity for Releases 1 and 2 and Releases 4 and 5. (O) Time of expected high tide (new/full moon). See 'Materials and methods' for details
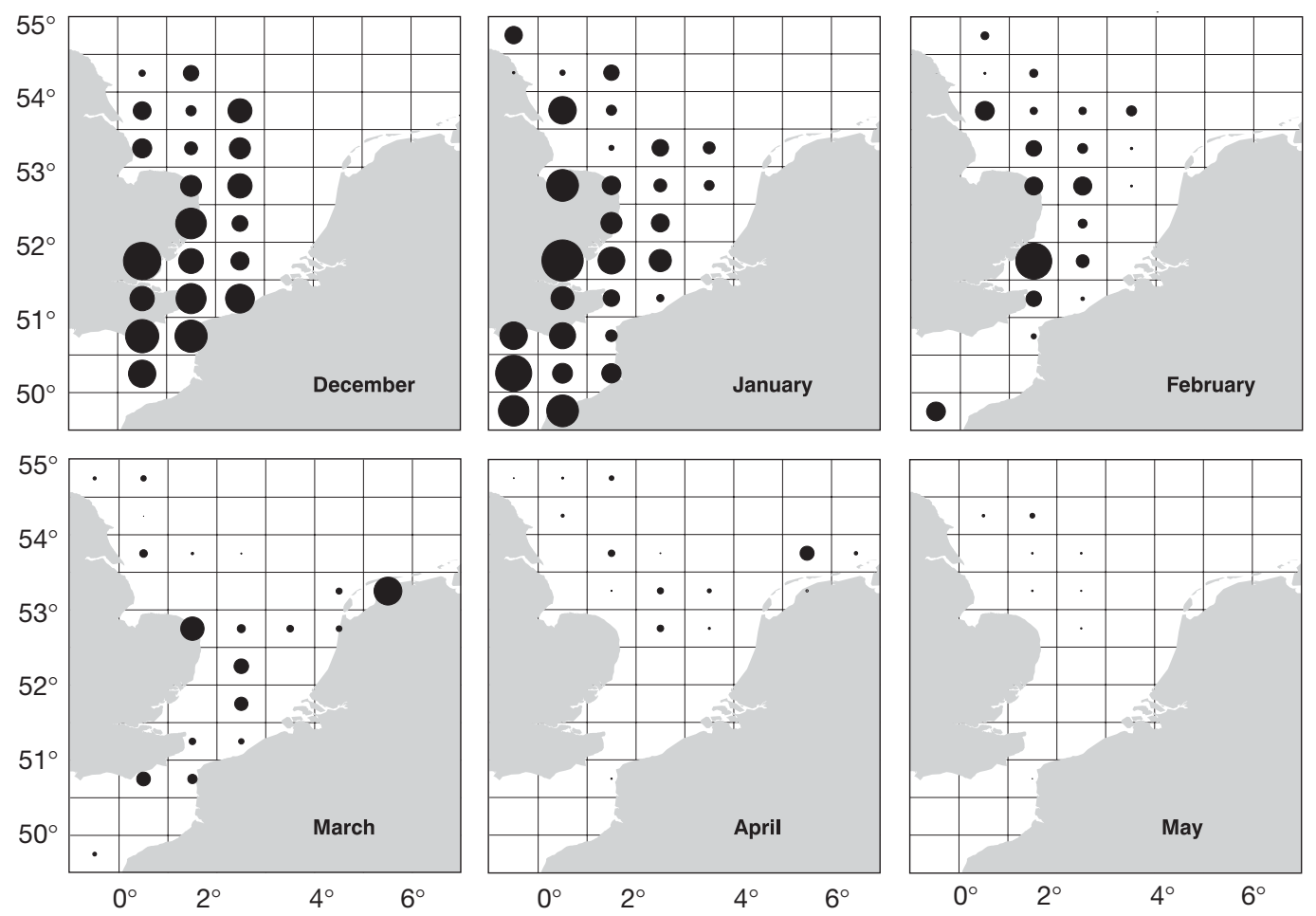

Fig. 6. Pleuronectes platessa. Monthly plots illustrating proportion of time spent swimming in midwater per ICES rectangle, December to May, based on the results from $\mathrm{n}=19$ (December), $\mathrm{n}=27$ (January), $\mathrm{n}=16$ (February and March), $\mathrm{n}=10$ (April) and $n=8$ (May) plaice respectively. Size of the circles is proportional to average number of hours spent in midwater per ICES rectangle; largest circles $=15 \mathrm{~h}$, the longest average swimming time observed 


\section{DISCUSSION}

We were able to identify clear patterns of rhythmic behaviour in the vertical activity of plaice in the southern North Sea, which varied both spatially and temporally in relation to the annual migration cycle. These results confirm earlier observations on the behaviour of migrating southern North Sea plaice, and extend these to the context of the annual migratory cycle. The results have important implications for the availability of plaice to capture by trawling, and also the accessibility of plaice to acoustic and trawl-based assessment surveys.

\section{Behaviour of migrating plaice}

Our results demonstrate that midwater swimming activity of plaice was most pronounced during migration, and that following completion of the post-spawning migration, plaice rarely left the seabed. There was some indication that the fish spent less time in midwater during the post-spawning than during the prespawning migration. We confirmed previous observations that migrating plaice exhibited circatidal vertical activity patterns (Greer Walker et al. 1978, Arnold \& Metcalfe 1996, Hunter et al. 2004b). Most plaice showed both circadian and circatidal elements of rhythmicity in their swimming activity, with the circadian element being the more significant. This finding highlights the tendency towards nocturnal activity in plaice. It is noted, however, that since the phase relationship between the transporting tide and the light-dark cycle changes by $0.8 \mathrm{~h}$ in every $24 \mathrm{~h}$, there are periods when 2 transporting tides occur at night, especially during winter in the southern North Sea, when the duration of darkness is up to $15 \mathrm{~h}$. The true extent of tidal activity may therefore be masked because migration occurs primarily during winter.

We observed a distinct change from circatidal vertical activity (indicative of migration using selective tidal stream transport: Greer Walker et al. 1978), to circadian vertical activity after the plaice had reached their spawning areas. Behaviour in the spawning ground was characterised by predominantly circadian rhythms. Nichols (1989) reported a clear diel rhythm in the spawning of plaice in the southern North Sea. Most spawning occurred at night, reaching a peak before midnight and declining steadily towards dawn, with only sporadic spawning during the daytime (Nichols 1989).

In all cases, the plaice spent less time swimming in midwater during the spawning period than during migration. In 2 plaice that recorded data over a full annual migration cycle (Plaice 21 and 31, Fig. 3), resi- dency in the spawning ground appeared to be split into 2 phases. An initial active phase of either random (Plaice 21) or circadian (Plaice 31) behaviour was followed by a period where the fish remained resting on the seabed. This suggests that a short recovery period may be required following spawning, before embarking on the return migration (Arnold \& Metcalfe 1996). While spawning physiology may dictate a post-spawning rest in females, males may not be affected in the same way. It is noted, however, that the fish do not feed during either spawning (Rijnsdorp 1989) or migration (Arnold \& Metcalfe 1996). Alternatively, plaice may also require to re-orientate in order to successfully navigate the post-spawning migration. External cues used for navigation are still poorly understood (Metcalfe et al. 1993).

Identification of discrete blocks of rhythmic behaviour should make the interpretation of future studies of plaice migration simpler, since the sequence of vertical activity patterns appear to be similar, irrespective of their location in the southern North Sea (Fig. 4). However, our study did not extend to the central and northern areas of the North Sea, where slow, tidal current velocities prohibit the use of selective tidal stream transport (Hunter et al. 2004a). It remains to be seen, therefore, whether similar phases of activity can be identified in areas where migration appears to be achieved by directed swimming on the seabed (Hunter et al. 2004a).

Our results also revealed that the vertical activity patterns of plaice were related to the spring-neap cycle. Activity was suppressed with a periodicity of $336 \mathrm{~h}(14 \mathrm{~d})$, in phase with the spring-neap cycle. This suggests that as well as there being a threshold below which plaice are unable to take advantage of tidal stream transport (Metcalfe et al. 1990), there may also be a maximum tidal velocity above which swimming behaviour is suppressed. Previous work has demonstrated that in areas of fast-flowing tidal streams, plaice may have difficulty maintaining their position on the seabed during times of peak flow (Arnold \& Weihs 1978). If the fish do not move into midwater to escape the flow on the seabed, as suggested by our results, their other option would be to seek refuge by burying or sheltering in the lee of a sand wave (Gerstner \& Webb 1998). Alternatively, exposure to fast tidal streams during the spring-neap cycle may form part of the system whereby plaice synchronise their behaviour with the overall tidal cycle.

Our results demonstrate the behaviour of adult female plaice only, and it is possible, therefore, that the vertical activity patterns of males differ. For example, the predominance of males in midwater trawls on Southern Bight spawning grounds (Arnold \& Cook 1984) suggests that it is the male fish that seek out 
mates during spawning (Forster 1953, Solmundsson et al. 2003). Adult females in the Southern Bight spend up to $6 \mathrm{wk}$ in spawning grounds before their return migration, whereas male residency in Southern Bight spawning grounds can be up to 9 wk (Arnold \& Metcalfe 1996). Furthermore, paired-haul midwater trawling experiments have also demonstrated a southward migration of immature female plaice peaking in January, after the pre-spawning migration of the adults (Arnold \& Metcalfe 1996).

\section{Relevance to stock assessment}

Many forms of stock assessment, including the virtual population analyses routinely applied in fisheries management, draw on information gathered by surveys to tune data on stock numbers-at-age. Surveys are assumed to give unbiased estimates of the portion of the stock available to the survey, but with large variation due to the relatively small sample size (Aglen et al. 1999). The results of the present study clearly demonstrate systematic spatial and temporal variation in the vertical activity patterns of plaice. The plaice were vertically active mainly at night, with a predominantly diurnal pattern, and are not therefore uniformly accessible to survey by trawling (Harden Jones 1974, Walsh 1991, Aglen et al. 1999).

The English ground-fish survey of the North Sea is carried out during August/September each year using beam-trawling gear. We already know from studies using data storage tags that female plaice become active and start to migrate southwards from mid to late September (Hunter et al. 2004a). It is probable, therefore, that a varying fraction of the stock is not available to the survey due to nocturnal swimming. This effect could be even greater for male plaice, which arrive at the spawning grounds prior to females (Rijnsdorp 1989), and must therefore begin their migrations earlier. Furthermore, the summer eastern English Channel survey is carried out during daylight hours only. As our results suggest that plaice rarely leave the seabed during summer, a $24 \mathrm{~h}$ summer survey could considerably reduce costs and time, or extend the scope of the survey, which is aimed principally at plaice and sole.

The vertical activity of the fish may lead to a lack of complete coverage within survey areas, a situation that could produce faulty trends in survey indices. As further evidence for the potential significance of this effect, Bolle et al. (2001) calculated that conventional tagging studies in the southern North Sea could significantly underestimate the true distances migrated by plaice (as calculated from studies with electronic tags). This difference was partially attributed to plaice being less accessible to capture by trawling vessels during the migratory period. Assuming that the accessibility of plaice to capture by beam trawl is greatest when the fish are located on the seabed, then our results suggest that daytime trawls between May and August would provide the most accurate survey results.

The outcome of surveys can further be affected where the spatial dynamics of fish stocks are incompletely understood. Changes in the geographical distribution of a stock relative to the survey area could lead to higher or lower survey indices (Harden Jones 1974). Changes in geographical distribution can be caused by changes in migratory patterns or by changes when commercial fleets are fishing more heavily in some areas (local depletion), or both (e.g. Dinmore et al. 2003). In addition to providing information on vertical activity, data storage tags can provide fisheriesindependent data (Hunter et al. 2003a) on the spatial dynamics of fish stocks and the behavioural mechanisms which give rise to them.

In designing future surveys and deciding how to interpret their findings, it is suggested that the behaviour of fishes will need to be adequately accounted for in the calculation of survey indices of abundance (ICES 2002). The results of the present study illustrate how this information can be provided. Future studies of spatial and temporal variation in the vertical activity patterns of plaice need to focus on the behaviour of male fish, and behaviour in the northern and central North Sea, where alternative migration strategies may be predicted to result in very different vertical activity patterns (Hunter et al. 2004a).

Acknowledgements. This work was funded by the Department of Environment, Food and Rural Affairs (formerly MAFF), and the Commission of European Communities Agriculture and Fisheries (FAIR) specific RTD programme, PL962079, 'Migration, distribution and spatial dynamics of plaice and sole in the North Sea and adjacent areas'. It does not necessarily reflect their views and in no way anticipates the Commission's future policy in this area. Final versions of the figures were prepared by I. Gooch. Comments from 5 anonymous referees contributed significantly to the final version of this manuscript. The authors wish to thank everyone involved in the release of tagged plaice and return of the electronic tags.

\section{LITERATURE CITED}

Aglen A, Engås A, Huse I, Michalsen K, Stensholt BK (1999) How vertical fish distribution may affect survey results. ICES J Mar Sci 56:345-360

Albert OT, Eliassen JE, Høines Å (1998) Flatfishes of Norwegian coasts and fjords. J Sea Res 40:153-171

Arnold GP (1981) Movements of fish in relation to water currents. In: Aidley DJ (ed) Animal migration. Soc Exp Biol Semin Ser 13:55-79

Arnold GP (2000) Unravelling mechanisms of fish migration: a 30-yr perspective. In: Hancock DA, Smith DC, Koehn JD 
(eds) Fish movement and migration. Australian Society for Fish Biology, Sydney, p 44-54

Arnold GP, Cook P (1984) Fish migration by selective tidal stream transport: first results with a computer simulation model for the European continental shelf. In: McCleave JD, Arnold GP, Dodson JJ, Neill WH (eds) Mechanisms of migration in fishes. Plenum Press, New York, p 227-261

Arnold GP, Dewar H (2001) Electronic tags in marine fisheries research: a 30-yr perspective. In: Sibert JR, Nielsen JL (eds) Electronic tagging and tracking in marine fisheries. Kluwer Academic Publishers, Dordrecht, p 7-64

Arnold GP, Metcalfe JD (1996) Seasonal migrations of plaice (Pleuronectes platessa) through the Dover Strait. Mar Biol 127:151-160

Arnold GP, Weihs D (1978) A hydrodynamic study of rheotaxis in the plaice (Pleuronectes platessa L.). J Exp Biol 75:147-170

Bolle LJ, Hunter E, Rijnsdorp AD, Pastoors MA, Metcalfe JD, Reynolds JD (2001) Do tagging experiments tell the truth? Using electronic tags to evaluate conventional tagging data. ICES CM 2001/0:2

Buckley AA, Arnold GP (2001) Orientation and swimming speed of plaice migrating by selective tidal stream transport. In: Sibert JR, Nielsen JL (eds) Electronic tagging and tracking in marine fisheries. Kluwer Academic Publishers, Dordrecht, p 315-330

Charnock H, Dyer KR, Huthnance JM, Liss PS, Simpson JH, Tett PB (1994) Understanding the North Sea system. Chapman \& Hall, London

Creutzberg F, Eltink ATGW, Van Noort GJ (1978) The migration of plaice larvae Pleuronectes platessa into the western Wadden Sea. In: McLusky DS, Berry AJ (eds) Physiology and behaviour of marine organisms. Proc 12th Eur Mar Biol Symp. Pergamon Press, Oxford, p 243-251

De Groot SJ (1964) Diurnal activity and feeding habits of plaice. Rapp P-V. Réun Cons Int Explor Mer 155:48-51

De Groot SJ (1971) On the interrelationships between morphology of the alimentary tract, food and feeding behaviour in flatfishes (Pisces: Pleuronectiformes). Neth J Sea Res 5:121-196

Dinmore TA, Duplisea DE, Rackham BD, Maxwell DL, Jennings S (2003) Impact of large-scale area closure on patterns of fishing disturbance and the consequences for benthic communities. ICES J Mar Sci 60:371-380

Dörrscheidt GJ, Beck L (1975) Advanced methods for evaluating characteristic parameters $(\tau, \alpha, \rho)$ of circadian rhythms. J Math Biol 2:107-121

Enright JT (1965) The search for rhythmicity in biological time-series. J Theor Biol 8:426-468

Forster GR (1953) The spawning behaviour of the plaice. J Mar Biol Assoc UK 32:319

Gerstner CL, Webb PW (1998) The station-holding performance of the plaice. Pleuronectes platessa on artificial substratum ripples. Can J Zool 76:260-268 (1998)

Gibson RN (1973) Tidal and circadian activity rhythms in juvenile plaice, Pleuronectes platessa. Mar Biol 22: 379-386

Gibson RN (1982) The effect of hydrostatic pressure cycles on the activity of young plaice Pleuronectes platessa. J Mar Biol Assoc UK 62:621-635

Gibson RN (1997) Behaviour and distribution of flatfishes. J Sea Res 37:241-256

Gibson RN, Blaxter JHS, De Groot SJ (1978) Developmental changes in the activity rhythm of the plaice (Pleuronectes platessa L.). In: Thorpe JE (ed) Rhythmic activity of fishes. Academic Press, London, p 169-186

Godø OR (1994) Factors affecting the reliability of groundfish abundance estimates from bottom trawl surveys. In: Fernö A, Olsen S (eds) Marine fish behaviour in capture and abundance estimation. Fishing News Books, Oxford, p 166-199

Godø OR, Michalsen K (2000) Migratory behaviour of north east Arctic cod, studied by use of data storage tags. Fish Res 48:127-140

Greer Walker M, Harden Jones FR, Arnold GP (1978) The movements of plaice (Pleuronectes platessa L.) tracked in the open sea. J Cons Int Explor Mer 38:58-86

Harden Jones FR (1974) Objectives and problems related to research into fish behaviour. Sea Fish Res:261-275

Harden Jones FR, Arnold GP, Greer Walker M, Scholes P (1979) Selective tidal stream transport and the migration of plaice (Pleuronectes platessa L.) in the southern North Sea. J Cons Int Explor Mer 38:331-337

Harding D, Nichols JH, Tungate DS (1978) The spawning of plaice (Pleuronectes platessa L.) in the Southern Bight. Rapp P-V Réun Cons Int Explor Mer 172:102-113

Harris GJ, Morgan E (1983) Estimates of significance in periodogram analysis of damped oscillations in a biological time-series. Behav Anal Lett 3:221-230

Hjellvik V, Godø OR, Tjostheim D (2001) Modeling diurnal variation of marine populations. Biometrics 57:189-196

Hunter E, Aldridge JN, Metcalfe JD, Arnold GP (2003a) Geolocation of free-ranging fish on the European continental shelf as determined from environmental variables. I. Tidal location method. Mar Biol 142:601-609

Hunter E, Metcalfe JD, Reynolds JD (2003b) Migration route and spawning area fidelity by North Sea plaice. Proc R Soc B 270:2097-2103

Hunter E, Metcalfe JD, Arnold GP, Reynolds JD (2004a) Impacts of migratory behaviour on population structure in North Sea plaice. J Anim Ecol 74:377-385

Hunter E, Metcalfe JD, Holford BH, Arnold GP (2004b) Geolocation of free-ranging fish on the European continental shelf as determined from environmental variables. II. Reconstruction of plaice ground-tracks. Mar Biol 144: $787-779$

ICES (2002) Report of the Working Group on Methods on Fish Stock Assessments, ICES Headquarters, Copenhagen, Denmark, 3-7 December 2001. Int Counc Explor Sea Comm Meet 2002/D:01

Jørgensen OA (1997) Pelagic occurrence of Greenland halibut Reinhardtius hippoglossoides (Walbaum), in west Greenland waters. J Northw est Atl Fish Sci 21:39-50

Kell LT, Scott R, Hunter E (2004) Implications for current management advice for North Sea plaice. Part I. Migration between the North Sea and English Channel. J Sea Res 52:287-299

Kuipers B (1973) On the tidal migration of young plaice (Pleuronectes platessa) in the Wadden Sea. Neth J Sea Res 6: 376-388

McQuinn IH (1997) Metapopulations and the Atlantic herring. Rev Fish Biol Fish 7:297-329

Metcalfe JD, Arnold GP (1997) Tracking fish with electronic tags. Nature 387:665-666

Metcalfe JD, Arnold GP (1998) Tracking migrating fish with electronic tags. In: McCarthy M (ed) EEZ technology: a review of advanced technologies for the management of EEZs worldwide, 2nd edn. ICG Publishing, London, p 199-206

Metcalfe JD, Arnold GP, Webb P (1990) The energetics of migration by selective tidal stream transport: an analysis for plaice tracked in the southern North Sea. J Mar Biol Assoc UK 70:149-162

Metcalfe JD, Holford BH, Arnold GP (1993) Orientation of 
plaice (Pleuronectes platessa) in the open sea: evidence for the use of external directional clues. Mar Biol 117:559-566

Metcalfe JD, Arnold GP, McDowall PW (2002) Migration. In: Hart PJB, Reynolds JD (eds) Handbook of fish biology and fisheries, Vol 1. Fish biology. Blackwell Publishing, Oxford, p 175-199

Michalsen K, Godø OR, Fernö A (1996) Diel variation in the catchability of gadoids and its influence on the reliability of abundance indices. ICES J Mar Sci 53:389-395

Nichols JH (1989) The diurnal rhythm in spawning of plaice (Pleuronectes platessa L.) in the southern North Sea. J Cons Int Explor Mer 45:277-283

Page NS (1996) Rhythmic behaviour in two species of marine flatfish: solenette (Buglossidium luteum Risso) and plaice (Pleuronectes platessa L.). PhD thesis, University of Birmingham

Righton D, Metcalfe JD (2002) Multi-torsking: simultaneous measurements of cod behaviour show differences between North Sea and Irish Sea stocks. Hydrobiologia 483: 193-200

Righton D, Metcalfe JD, Connolly P (2001) Electronic tags reveal behavioural differences between North Sea and Irish Sea cod. Nature 411:156

Editorial responsibility: Otto Kinne (Editor),

Oldendorf/Luhe, Germany
Rijnsdorp AD (1989) Maturation of male and female North Sea plaice (Pleuronectes platessa L.). J Cons Int Explor Mer 46:35-51

Rijnsdorp AD, van Stralen M, van der Veer HW (1985) Selective tidal transport of North Sea plaice larvae Pleuronectes platessa in coastal nursery areas. Trans Am Fish Soc 114: $461-470$

Sokolove PG, Bushell WN (1978) The chi-square periodogram: its utility for analysis of circadian rhythms. J Theor Biol 72:131-160

Solmundsson J, Karlsson K, Palsson J (2003) Sexual differences in spawning behaviour and catchability of plaice (Pleuronectes platessa) west of Iceland. Fish Res 61:57-71

Stensholt B (2001) Cod migration patterns in relation to temperature: analysis of storage tag data. ICES J Mar Sci 58: 770-793

Verheijen FJ, De Groot SJ (1967) Diurnal activity pattern of plaice and flounder (Pleuronectidae) in aquaria. Neth $\mathrm{J}$ Sea Res 3:383-390

Walsh SJ (1991) Diel variation in availability and vulnerability of fish to a survey trawl. J Appl Ichthyol 7:147-159

Wheeler A (1969) The fishes of the British Isles and northwestern Europe. Macmillan, London

Submitted: February 12, 2004; Accepted: May 27, 2004

Proofs received from author(s): September 7, 2004 